BULLETIN Bulletin hispanique

HISPANIQUE Université Michel de Montaigne Bordeaux

116-1 | 2014

Varia

\title{
Estudio de los rasgos estilísticos en la versión española de la Histoire Naturelle générale et particulière
}

Antonia Montesinos Oltra

\section{(2) OpenEdition}

Journals

Edición electrónica

URL: http://journals.openedition.org/bulletinhispanique/3155

DOI: 10.4000/bulletinhispanique.3155

ISSN: 1775-3821

Editor

Presses universitaires de Bordeaux

Edición impresa

Fecha de publicación: 1 junio 2014

Paginación: 191-218

ISBN: 978-2-86781-931-5

ISSN: 0007-4640

Referencia electrónica

Antonia Montesinos Oltra, « Estudio de los rasgos estilísticos en la versión española de la Histoire Naturelle générale et particulière », Bulletin hispanique [En línea], 116-1 | 2014, Publicado el 01 junio 2017 , consultado el 23 mayo 2020. URL : http://journals.openedition.org/bulletinhispanique/3155; DOI : https://doi.org/10.4000/bulletinhispanique.3155 


\title{
Estudio de los rasgos estilísticos en la versión española de la Histoire Naturelle générale et particulière
}

\author{
Antonia Montesinos Oltra \\ Universidad de Valencia - España
}

Buffon publie en 1749 le premier volume de sa monumentale Histoire Naturelle. La version espagnole est totalement fidèle pour ce qui est du contenu scientifique; mais le traducteur introduit, en lien avec ses intentions de communication, des changements de style significatifs qui touchent aussi à la relation de son texte avec les genres scientifiques.

Mots clés : XVIII ${ }^{e}$ siècle, traduction, discours scientifique, histoire naturelle, style.

Buffon publica en 1749 el primer volumen de su monumental Histoire Naturelle. La versión española es completamente fiel en el contenido cientifico; pero el traductor introduce significativos cambios de estilo, relacionados con sus intenciones comunicativas, y que, además, afectan a la caracterización estilística de la obra dentro de los géneros científicos.

Palabras clave: siglo XVIII, traducción, discurso científico, historia natural, estilo.

In 1749, Buffon published the first volume of his monumental study "Histoire Naturelle". Although the Spanish version remains faithful to the scientific content of the original, the translation contains significant stylistic changes. These changes of style are attributable to the translator's communicative goals, and affect the categorisation of the translated work within the genres of scientific writing.

Key words: $18^{\text {th }}$ century, translation, scientific discourse, natural history, style.

1. Este trabajo está basado, en parte, en varios capítulos de nuestra tesis doctoral La traducción cientifica en España en el siglo XVIII. Estudio de la versión española (1785-1805) de la Histoire Naturelle de Buffon por J. Clavijo y Fajardo, Valencia, Universitat de Valencia, 2011.

Bulletin Hispanique, Tome 116, n 1 - juin 2014 - p. 191-218. 


\section{EL SIGLO XVIII Y LA NUEVA CIENCIA}

En Inglaterra, Francia y otros países europeos, la ciencia moderna surgida de la revolución baconiana experimenta importantes transformaciones a lo largo del siglo XVIII, favorecidas tanto por la institucionalización como por la profesionalización de los grupos de científicos, muchos de ellos pertenecientes a las Academias de Ciencias, surgidas ya en el siglo anterior ${ }^{2}$. España, en cambio, sigue manteniéndose prácticamente al margen en el cultivo de la nueva ciencia: no hay ni grupos de científicos ni instituciones científicas como las Academias de Ciencias. Si nos ceñimos a la Historia Natural, la Botánica es el ramo más cultivado, pero hay que esperar hasta 1755 para ver la fundación del Real Jardín Botánico. El Real Gabinete de Historia Natural (RGHN en adelante) no nacerá hasta 1777 , y, en este caso, casi puede decirse que la Institución se creó sin que apenas hubiera naturalistas en España. La Academia de Ciencias española no verá la luz hasta bien entrado el siglo XIX: de 1834 es la Real Academia de Ciencias Naturales de Madrid, suprimida en 1847 al crearse la Academia de Ciencias Exactas, Físicas y Naturales.

En este contexto de penuria científica, las traducciones, en su gran mayoría de obras francesas, representan el principal vínculo y vía de acceso a la nueva ciencia para los españoles. A diferencia de otras ciencias o artes (como la Química o la Medicina, por ejemplo), no existen grupos de profesionales ni apenas aficionados que se dediquen a cultivar la Historia Natural. Por ello, el traductor de la Histoire Naturelle de Buffon, Joseph G. Clavijo y Fajardo -que tampoco era naturalista-, decide dirigir la obra a la juventud, para instruirla en las bases de esta ciencia e incitarla a que se dedique a ella, con el fin de que en el futuro España pueda situarse al nivel de los países de su entorno.

Buffon escribe su Histoire Naturelle générale et particulière para un público heterogéneo, como afirma Condorcet en su Éloge de M. le Comte de Buffon ${ }^{3}$

M. DE BUFFON a écrit pour les savants, pour les philosophes et pour le public, et il a sçu proportionner la clarté de chaque partie, au désir quil avoit d'être entendu d'un nombre plus ou moins grand de lecteurs. (56-57)

Y Ch. G. de Lamoignon de Malesherbes afirma, en sus Observations sur l'Histoire Naturelle Générale et Particulière de Buffon et Daubenton ${ }^{4}$, que, gracias a la belleza de su estilo, tan distinto a la «lengua de los naturalistas», Buffon ha conseguido la adhesión «des gens du monde»:

2. Swann Paradis, Imagination, jugement, génie : la fabrique des quadrupèdes dans l'Histoire naturelle de Buffon (1707-1788), Canada, Université Laval, Collection Mémoires et thèses électroniques, 2008, ch. I, p. 3.

3. Éloge de M. le Comte de Buffon, par M. le Marquis de Condorcet, Paris, Buisson, 1790.

4. Ch. G. de Lamoignon de Malesherbes, Observations sur l'Histoire Naturelle Générale et Particulière de Buffon et Daubenton, Paris, Ch. Pougens. An VI (1798). En Buffon et l'histoire naturelle: l'édition en ligne. http://www.buffon.cnrs.fr/jugements/recensions.php 
L'art qu'a toujours eu $M$. de Réaumur de traiter des sujets intéressans et de rendre intéressant [sic] ceux quil a traités l'a rendu le naturaliste des gens du monde; qualité quil a réunie à beaucoup d'autres plus solides qui lui ont mérité l'estime des étrangers comme celle de ses compatriotes. Je conviens que ce titre est fait pour exciter l'émulation de $M$. de Buffon. En effet, il est certain que ceux pour qui $M$. de Buffon a écrit ne sont point les naturalistes; je suis même persuadé que quand il a entrepris son ouvrage, il les connoissoit à peine de nom. Ceux dont il a cherché l'approbation sont, selon les apparences, les gens du monde, les gens d'esprit, les gens de goût; i la la beauté de son style, surtout les traits brillans dont son ouvrage est rempli, lui assurent à jamais leurs suffrages.

Mais ce ne sont point là ceux dont $M$. de Jussieu et M. Guettard ont mérité l'estime. L'un et l'autre n'ont jamais parlé que la langue des naturalistes, souvent peu intelligible, et presque toujours rebutante pour ceux qui n'y sont point habitués. Ils n'ont jamais traité par préférence ces sujets qui de tems en tems sont à la mode, et qui peuvent seuls fixer sur les naturalistes, l'attention du public. (107) (Las cursivas son nuestras)

Clavijo y Fajardo -que tenía una valiosa experiencia previa como escritor y como traductor de obras teatrales y religiosas -destaca, asimismo, el carácter singular de la obra y estilo de Buffon, en los límites difusos entre la Historia Natural y les belles-lettres.

... que en su Historia Natural no debe admirarse ménos la profundidad y la extension de sus investigaciones, que la fuerza y solidez de sus raciocinios, la nobleza y la pureza de su estilo, y la armonia y claridad de su expresion: y que en la misma Obra, llena de descripciones amenas, de imágenes agradables y de reflexînes profundas, se encuentra reunido lo que tiene de mas curioso la Física, de mas sublime la eloqüencia y de mas brillante la Poesía, siendo todavía mas admirable en ella el órden que reyna en las diversas partes de tan vasto edificio. (Prólogo, LVIII).

Al realizar su versión, destinada específicamente a la juventud, Clavijo y Fajardo es completamente fiel en el contenido; añade numerosas notas para justificar el uso de neologismos ${ }^{6}$, para facilitar la comprensión de los términos científicos de distintas especialidades a sus lectores, o para actualizar el contenido científico de la obra -pues la traducción no empezó a publicarse hasta más de tres décadas después que la obra original. Sin embargo, como

5. Valoraciones que reiteran los estudios más recientes. Así, Paradis (idem, 3-4): « [...] la posture même du naturaliste qui va, peut-être plus que le chimiste, le géomètre ou l'astronome, participer de ce transfert de capital symbolique en "revêtant la dégaine de l'écrivain pour se présenter au public, s'efforçant de rendre par là [son] savoir attrayant". Sans renier le mouvement général par lequel les Lumières comptaient dissiper ignorance et préjugés afin qu’advienne un jour le bonheur sur terre, les naturalistes écrivaient souvent pour attirer le lectorat selon des stratégies où leur sujet était modulé pour être plus "commercialisable". À la recherche de la gloire ou de la fortune, ces derniers devaient viser un plus large public que celui de l'Académie des sciences. L'histoire naturelle, incluant des textes qui visaient à la fois la persuasion et la diffusion d'un savoir, aura donc été, à tout le moins en partie, une "entreprise rhétorique" dont Buffon fut peut-être le plus célèbre représentant. "

6. Antonia Montesinos Oltra, «Neologismos de la Historia Natural en la traducción de la Histoire Naturelle générale et particulière de Buffon por Joseph Clavijo y Faxardo ", en Cuadernos de Filología Francesa, n 22, monográfico sobre la traducción no literaria en España (francés / español): siglos XVIII y XIX, Cáceres, Universidad de Extremadura, 2011, pp. 141-159. 
vamos a demostrar en este trabajo, realiza importantes cambios en los rasgos de estilo. Tales cambios, que no afectan al contenido científico de la obra, son elegidos por el traductor en función de su intención comunicativa, y tienen, además, repercusiones en el nivel estilístico del género.

\section{Clavijo y fajardo, traductor literario}

En 1770 -siete años antes de su nombramiento en el RGHN-Clavijo y Fajardo, bajo la protección del ministro Campomanes, fue nombrado director de la compañía de teatro creada - por «iniciativa del conde de Aranda y del ministro Grimaldi, tomando como base la compañía formada en Sevilla a instancias de Olavide» ${ }^{7}$ - para actuar en los Teatros de los Reales Sitios, cargo que desempeñó hasta la disolución de la compañía en 1777. Casi simultáneamente, desde 1773 hasta 1779, está también al frente del Mercurio Histórico y Político de Madrid, que antes había dirigido Tomás de Iriarte. Según Lafarga (idem, 253), para que la compañía de los Reales Sitios tuviera «un repertorio digno, moderno y regular», "a falta de obras espańolas hubo que recurrir a la traducción de piezas francesas» ${ }^{8}$.

Clavijo y Fajardo realizó tres traducciones: Le glorieux de Destouches como El vanaglorioso, Andromaque de Racine como La Andrómica y Le légataire universel de Regnard como El heredero universal. A estas habría que añadir, como indica Viera y Clavijo ${ }^{9}$ (p. 545), el sainete Beltrán en el Serrallo, y algo no menos importante, como señala también Viera, el hecho de que Clavijo corrigiera «la mayor parte de los Dramas que se representaron durante aquel periodo de tiempo» (ibidem).

El juicio global que merecen, según Lafarga (idem, pp. 236-7), Clavijo y Fajardo y los otros traductores no puede ser más favorable: son hombres de

7. Francisco Lafarga, «El siglo XVIII, de la Ilustración al Romanticismo», en F. Lafarga, y L. Pegenaute (eds.), Historia de la traducción en España, Salamanca, Ed. Ambos Mundos, 2004, pp. 209-319.

8. En la nómina que da este autor figuran, junto a Clavijo, «traductores» como Iriarte y Olavide: «Aun cuando las referencias que nos han llegado, a través de distintas fuentes, no son coincidentes, puede establecerse la siguiente lista: de Beaumarchais se tradujo Eugénie por L. Reynaud (perdida); de Chamfort Le marchand de Smyrne por Iriarte; de L. De Belloy Zelmire por Olavide; de Destouches Le dissipateur (como El malgastador) y Le philosophe marié por Iriarte, Le glorieux por Clavijo como El vanaglorioso; de Fagan La pupille por Iriarte con el título de La pupila juiciosa; de Mme de Graffigny Cénie por Engracia Olavide; de Gresset Le méchant por Iriarte como El mal hombre; de Lemierre Hypermnestre por Olavide; de Marivaux L école des mères por traductor desconocido; de Mercier Le déserteur por Olavide; de Molière Le malade imaginaire por Iriarte como El aprensivo (perdida); de Piron Gustave Wasa por Miguel Maestre; de Racine Andromaque por Clavijo, Iphigénie por A. Pérez de Guzmán y Phèdre por Olavide; de Regnard, Le joueur por Olavide y Le légataire universel por Clavijo; de Voltaire, L'Écossaise y L'orphelin de la Chine por Iriarte, y Mérope y Olympie por Olavide.» (Lafarga, ibidem).

9. José Viera y Clavijo, Noticias de la historia general de Las Islas de Canaria, Madrid, Blas Román, Tomo Quarto, 1783, pp. 542 - 546. 
letras que conocen los preceptos de la traducción; que, antes de traducir, buscan la edición más fiable del texto; que realizan una labor previa de documentación y análisis; y que, después, pulen, liman y corrigen, e incluso someten su trabajo a la corrección y cotejo con el original por parte de amigos o expertos. En suma, el proceso que siguen para traducir se inscribe perfectamente en lo que denomina la «profesionalización» del traductor.

Lo que nos interesa, pues, es el hecho de que Clavijo, en la década que precede a su llegada al RGHN, no sólo ha realizado una serie de traducciones, sino que, además, forma parte de un grupo de creadores-traductores que trabajan con sumo rigor a lo largo de todo el proceso de la traducción.

Además, según Viera y Clavijo (ibidem), a las ya mencionadas han de sumarse en el haber de Clavijo y Fajardo tres traducciones de obras relacionadas con asuntos religiosos -y políticos, en el caso de los jesuitas- que realizó a partir de 1767: Conferencias y discursos sinodales sobre las principales obligaciones de los eclesiásticos, con una colección de cartas pastorales sobre diferentes asuntos, de Masillon; el «Discurso en el qual se investiga qual fue la religion primitiva», que precedía al Diccionario histórico de las heregias, errores y cimas [sic], del abate Pluquet; y Los Jesuitas reos de lesa Magestad (Les Jésuites criminels de lèse-majesté dans la théorie et dans la pratique. La Haye, 1758). Estas circunstancias son, por tanto, inmejorables como punto de partida para la ingente tarea en solitario que Clavijo se propondrá poco después al decidir traducir la obra de Buffon; aunque, por supuesto, la traducción de la Histoire Naturelle comportaría problemas de doble cariz - unos de carácter traductológico, y otros de carácter lexicológico- que nada tenían que ver con las traducciones anteriores.

\section{LA HISTORIA NATURAL GENERAL Y PARTICULAR por Joseph Clavijo y Fajardo}

Joseph Clavijo y Fajardo publicó, desde 1785 hasta 1805, veintiún tomos de la Historia Natural general y particular del Conde de Buffon, que incluían la Teórica de la Tierra, la Historia general de los animales, la Historia natural del hombre, la historia de los Cuadrúpedos y de las culebras, además de los Suplementos con adiciones a los tomos anteriores que Buffon publicó más tarde. De esos veintiún tomos, los tres últimos se corresponden con los manuscritos originales dejados por el Conde de Buffon a su muerte, cuya impresión corrió a cargo del Conde de La Cépède.

No sabemos cuándo empezó su traducción Clavijo y Fajardo, pues los datos que conocemos son contradictorios. El oficio con la Real Orden en la que se le nombraba Formador de Índices del RGHN es del 1 de enero de 1777, y en su Prólogo del Traductor afirma que fue durante el desempeño de su labor cuando decidió traducir la Histoire Naturelle de Buffon. Dicha decisión fue el resultado de todo el proceso que tuvo que llevar a cabo para formar los Índices y el Catálogo de las producciones naturales en el Real Gabinete. Según explica, 
tras nueve años leyendo y cotejando todas las obras castellanas de Historia Natural que pudo encontrar con las de los autores latinos y franceses, para hallar las voces que necesitaba, se dio cuenta del atraso de los españoles en el estudio de la historia natural, salvo en Botánica (Prólogo, IV-V). Y decidió traducir "para instrucción de la juventud, la mejor obra de Historia Natural que, á juicio de los sabios, se conociese» (Prólogo, VI). Puede afirmarse, por tanto, que Clavijo y Fajardo -cuya formación y experiencia anteriores nada habían tenido que ver con la ciencia- no habría traducido la obra de Buffon de no haber sido nombrado para formar los índices y el catálogo científico, y llevar la correspondencia en el Real Gabinete.

Lo único cierto es que a principios de 1781 ya tenía traducidos los dos primeros tomos, puesto que fueron entregados entonces para su censura al Director del RGHN, Pedro Franco Dávila. Cuatro años más tarde, en enero de 1785 , este dio su dictamen favorable. El primer tomo de la traducción se publicó en 1785, en la imprenta de Joaquín Ibarra, impresor de Cámara de Su Majestad. A este tomo lo siguieron otros dos en 1786, y el resto, a razón de un tomo o, a veces, dos por año -aunque algunos años (1795, 1797, 1799-1801) no se publicara ninguno- hasta 1805, en que acabó la publicación con dos tomos, el XX y el XXI. Esta primera edición tuvo muy buena acogida, ya que seis años después de la publicación del primer tomo y el mismo año en que se publicó el X, en 1791, vio la luz el primer tomo de la segunda edición, también en la imprenta de Ibarra. Esta segunda edición se realizó de modo paralelo a la primera, desde 1791 hasta 1805, coincidiendo algunos años la publicación de tomos de ambas ediciones.

El MOTIVO DE LA TRADUCCiÓN:

LA FALTA DE CULTIVO DE LA HISTORIA NATURAL

El juicio de Joseph Clavijo y Fajardo -por entonces formador de índices del RGHN, pero ya vicedirector, con funciones y sueldo de director, en mayo de 1786; y director en 1795- es uno más en una larga serie de quejas por la falta de cultivo de la Historia Natural en España, lejanos ya los tiempos (siglo XVI y principios del XVII) en que los españoles -sobre todo los que viajaron o escribieron de la historia natural de América, como los Acosta, Hernández, Monardes, Barba o Igarza- destacaron en el estudio de todos sus ramos, como afirma el propio traductor

Quando digo que se halla atrasado entre nosotros el estudio del reyno Animal y de la Mineralogía, no pretendo ofender á mi Nacion, ni dar armas á sus émulos, dedicados, casi por instinto, á censurarla. Mi asercion solo significa que, á proporcion de lo que otras Naciones han adelantado en estas materias, especialmente desde fines del siglo anterior y principios del presente, en que con mayor esmero se han dedicado á su estudio, nos hallamos nosotros atrasados. [...] Sin embargo, en los siglos anteriores, en aquellos tiempos en que varias Naciones aspiraban á tener instrucción sin acertar en los medios de adquirirla, no fué España la última que se dedicó al estudio de la 
Historia Natural, y si no obtuvo la primacia, á lo ménos se anticipó á algunos de nuestros vecinos que ahora nos tratan con tanto ceño, descortesía, y aun injusticia, quando no debieran olvidar lo que nos deben en punto de erudicion y buen gusto, ni que en aquellos tiempos se enriqueciéron con nuestros despojos; y que, quando la Francia, todavía bárbara, y grosera, no tenia, propiamente hablando, idioma, artes ni ciencias (según el Abate de Condillac, tomo II, fol. 478), habia en España artes, habia ciencias,... (Prólogo, V).

Entre las escasas obras originales de Historia Natural publicadas en España en el siglo XVIII antes de que Clavijo tradujera la obra de Buffon, se encuentran las del religioso y misionero José Torrubia, Aparato para la Historia Natural Española ${ }^{10}$, de 1754; y la del irlandés William Bowles -quien había sido contratado para la Casa de la Geografía por Antonio de Ulloa a principios de la década de 1750-, Introducción á la historia natural, y á la geografia física de España ${ }^{11}$, de 1775. Ambos autores deploran la situación de la Historia Natural en España y, en el caso de Torrubia, la falta de interés y patrocinio de la Corona por esos ańos.

Este es el contexto en el que llegó a España en 1783 el artículo Espagne de N. Masson de Morvilliers, publicado en la Encyclopedie Methodique ou par ordre de Matières, en el tomo I, dedicado a la Géographie Moderne. Aunque este artículo se inscribía en la línea de crítica de la leyenda negra de la monarquía hispánica $^{12}$, en España la controversia interna surgida a raíz del ataque de Masson de Morvilliers, conocida como "polémica de la ciencia», «se transforma a partir de ese momento en una verdadera contienda civil» ${ }^{13}$, en la que también participó Clavijo y Fajardo desde su Prólogo (VIII-IX).

Y aquí entra mi reflexîon. Si en España ha reynado tanta ignorancia, y si los Españoles nada han escrito que sea apreciable, ¿á qué fin se han tomado unas Naciones tan cultas el trabajo de traducir y escoliar sus obras? Y si estas son útiles y las mismas Naciones se han aprovechado de ellas ¿por qué tanta ingratitud? Sin duda es mas fácil tratar de ignorante á toda una Nacion, que aprender su idioma y leer sus libros; y me persuado á que esta es una de las causas de que varias Naciones, y particularmente nuestros vecinos, hablen y escriban de las cosas de España tan erradamente como pudieran escribir de lo que pasa en el globo de la Luna.

10. José Torrubia, Aparato para la Historia Natural Española con la Solucion del gran Problema Physico, sobre la transmigracion de los cuerpos marinos à los mas altos Montes de España, y su petrificacion en ellos, Madrid, Herederos de Agustin e Gordejuela y Sierra, 1754. Véase el Prólogo.

11. Guillermo Bowles, Introduccion a la Historia Natural y á la Geografía fisica de España. Madrid, Francisco Manuel de Mena, 1775. Véase el Discurso Preliminar, pp. 1, 14 y 15.

12. Ma Pilar Pérez Cantó, «Un debate en torno a la modernidad: la crisis de los ochenta.» En Espacio, Tiempo y Forma, Serie II, Ha Moderna, t. 11, 1998, pp. 381-403.

13. Ricardo Pascual Santiso, El botánico José Quer (1695-1764), primer apolotista de la ciencia española, Valencia, Cuadernos valencianos de Historia de la Medicina y de la ciencia, 1970, p. 11. 
En esta controversia, la ciencia tiene su lugar -entre otros muchos asuntos: Gobierno, clero, Inquisición, agricultura, comercio, colonias de América... ${ }^{14}-$; sin embargo, lo que se dilucida en esta polémica no es, única y principalmente, la aportación de España a la ciencia y a su progreso en los siglos anteriores, y el estado de la ciencia en el propio siglo XVIII, sino la conveniencia o no para el país del cultivo de la ciencia

En este debate no se discutía tanto la existencia de cultura científica en España como la utilidad o inutilidad de las ciencias físico-naturales para promover el bienestar del país; mientras los renovadores defendían el cultivo de las ciencias naturales como medio de propiciar el desarrollo económico de España, los tradicionalistas -Forner fue uno de sus más claros exponentes-, satisfechos con la situación social existente, sólo veían en el cultivo de las nuevas ciencias naturales y de la nueva filosofía un germen de incredulidad y de desórdenes sociales, incompatibles ambos con la felicidad del país, abogando por el cultivo de las ciencias políticas, teológicas y militares, a las cuales debía España su grandeza y su imperio. ${ }^{15}$

Clavijo y Fajardo se alinea con los renovadores y defiende en su prólogo el cultivo de la Historia Natural (\$. IV. «Utilidades del estudio de la Historia Naturali, XXI-LVII) ${ }^{16}$.

\section{El DestinATARIO DE LA TRAdUCCiÓN: LA JUVENTUd ESPAÑOLA}

El formador de índices del RGHN declara que su finalidad es traducir la Histoire Naturelle de Buffon para instruir a la juventud española, para que la juventud estudie en ella los fundamentos de la Historia Natural y que, de este modo, el país salga del atraso en que se encuentra en esta importante ciencia

En este concepto, y para suplir aquella falta, me pareció que el mas claro testimonio que podia dar de mi gratitud á nuestro augusto Soberano, y el mayor servicio que podia hacer a mi patria, era traducir, para instrucción de la juventud, la mejor obra de Historia Natural que, á juicio de los sabios, se conociese (Prólogo, V-VI)

14. Antoni Cabanilles, en sus Observations sur l'article "Espagne» de la nouvelle encyclopédie, Paris, Imprimerie François-Ambroise Didot, 1784, empieza su apología con un repaso de «Science militaire, Marine, Beaux Arts (Architecture, Peinture, Gravure, Imprimerie), Manufactures, Littérature (Poésie, Éloquence) Histoire, Théologie, Jurisprudence, Mathématiques, Physique, Chymie, Histoire naturelle, Botanique. Médicine. Le caractère. Agriculture et industrie. Gouvernement (Elogio al gobierno de Carlos III). Le clergé (Elogio). Inquisition ». Después responde a la pregunta de Masson de Morvilliers : "Que devons nous à l'Espagne? qu'a-t-elle fait pour l'Europe depuis deux siècles, quatre siècles, dix siècles ?"

15. Ernesto y Enrique García Camarero, La polémica de la ciencia española (Introducción, selección y notas), Madrid, Alianza Editorial, 1970, pp. 9-10).

16. Antonia Montesinos Oltra, «Clavijo y Fajardo y la polémica de la ciencia en Espańa en el siglo XVIII en el Prólogo del Traductor a la Historia Natural del conde de Buffon.» En Juan Carlos de Miguel, Carlos Hernández, y Julia Pinilla, (eds). Enfoques de teoría, traducción y didáctica de la lengua francesa. Estudios dedicados a la profesora Brigitte Lépinette, València, Universitat de València, 2010. 
He dicho que el hallarme empleado en el Real Gabinete de Historia Natural, fue el motivo de aplicarme á este estudio; y no me parece fuera de propósito dar noticia del orígen del mismo Gabinete, de la facilidad que este proporciona para el estudio de la Historia Natural, y de la utilidad, objeto, límites y necesidad de esta Ciencia. En lo primero, cumpliré con la obligacion de fiel vasallo, no remitiendo al silencio, y acaso al olvido este establecimiento de nuestro amado Monarca; y en lo restante, ademas de desimpresionar á muchas personas que miran la Historia Natural como mera diversion ó como curiosidad infructuosa, me propongo excitar á la juventud Española á que se dedique á una Ciencia que reune en si lo útil y lo gradable [sic], y cuyo estudio debe ser considerado como parte muy principal de la buena educación. (Prólogo, IX)

Queriendo traducir la mejor Obra que se conociese de Historia Natural, con el fin de que la juventud Española estudie en ella los fundamentos de esta Ciencia importante, en que me prometo ha de hacer algun dia progresos, que causen emulacion á otras Naciones, no me fie de mi dictámen (Prólogo, LVII) (Las cursivas son nuestras)

\section{Los dos PRIMERos VOlÚmenes de LA HISTOIRE NATURELLE DE Buffon (I749) Y SU TRADUCCión POR Clavijo (I785-I787) ${ }^{17}$}

La Histoire Naturelle de Buffon estaba compuesta por 36 volúmenes. Clavijo y Fajardo publicó, como ya hemos señalado, un total de 21 tomos. Sería imposible, por tanto, sin tener todos estos volúmenes incorporados a una base de datos, realizar la comparación de los 21 tomos de la traducción con los correspondientes de la obra original.

Por esta razón, ha sido necesario delimitar para nuestro trabajo un corpus que pudiéramos estudiar sin la ayuda de medios técnicos, pero lo suficientemente extenso como para que nuestras conclusiones tuvieran cierto alcance. Por tanto, hemos elegido comparar los tomos I (349 páginas) y III (453 páginas) de la traducción de Clavijo y Fajardo con la primera parte de los tomos I (307 páginas) y II (426 páginas) de la obra original de Buffon, partes con las que aquellos se corresponden respectivamente.

\section{ESTILO Y RASGOS ESTILÍSTICOS}

La definición del concepto de estilo en la que basamos nuestro análisis es

El estilo es el conjunto de rasgos lingüísticos que caracterizan un texto por ser recurrentes y que tienen una función significativa y determinable relacionada con la intención comunicativa del autor.

17. Georges L. Leclerc Buffon, Histoire Naturelle générale et particulière, Paris, Impirmerie Royale, 1749 tomos I-II.

Georges L. Leclerc Buffon, Historia Natural general y particular, (traducción de J. Clavijo y Fajardo), Madrid, J. Ibarra, 1785-1786, tomos I y III. 
Para nosotros, el estilo, en primer lugar, no es propio de un autor -en el sentido de prejuzgar que todas sus obras hayan de tener necesariamente el mismo estilo o que se pueda reconocer la autoría de una obra a partir del análisis estilístico ${ }^{18}$-, sino de un texto concreto. En segundo lugar, la frecuencia es un factor necesario para que un rasgo lingüístico se considere rasgo estilístico en un texto determinado. En tercer lugar, la elección de dichos rasgos revela una intención, puesto que son rasgos funcionales y significativos; en este sentido, sí podemos decir que el estilo de un texto es propio del autor, puesto que es él quien ha realizado dicha elección.

Es innegable que, en función de su intención comunicativa, el autor elige el género y los modos del discurso (descripción, narración, exposición, argumentación); y que todo ello condiciona, hasta cierto punto, el estilo. Pero son condicionantes que el propio autor se impone por libre elección.

A la luz de este concepto de estilo, es evidente que el análisis cuantitativo a partir de las bases de datos facilita enormemente la labor de caracterización estilística de un texto; $y$, también, que el método comparativo es muy valioso, por la posibilidad que ofrece de ver opciones estilísticas distintas para un mismo asunto.

Para nuestro estudio, y en relación con la definición anterior de estilo, vamos a considerar que, en un texto concreto

Un rasgo estilistico es un rasgo lingüístico recurrente, elegido por el autor en función de sus intenciones comunicativas.

Nida y Taber, en su ya clásico estudio sobre la traducción bíblica $L a$ Traducción: teoría y práctica ${ }^{19}$, clasifican los rasgos estilísticos en "formales» y «léxicos» y les asignan dos funciones: bien aumentar la eficacia, es decir, «la máxima facilidad de descodificación con la mínima cantidad de energía en juego"; bien producir efectos especiales, es decir, aumentar el interés, producir mayor impacto y embellecer el mensaje (p. 191). Como subrayan en más de una ocasión, son muchos los rasgos formales y léxicos que se combinan en un texto para conseguir un estilo determinado, y por ello es muy difícil poder tratarlos todos. Dependiendo de la extensión del texto, puede aspirarse o no a la exhaustividad. En nuestro caso, y dado que el corpus está compuesto por dos de los tomos de la traducción y el texto original correspondiente, hemos

18. Como afirma Wolfgang Kayser, Interpretación y análisis de la obra literaria, Madrid, Gredos, 1970, p. 383: «Ni siquiera en el caso de naturalezas tan opuestas como las de Goethe y Schiller se ha conseguido distinguir mediante un análisis estilístico la participación del uno y del otro en el trabajo Xenien, que hicieron en común. [...] La causa de que una individualidad sea inasible no está sólo en su mutabilidad o en su «evolución». Tan imposible será fijarla en un estado determinado mediante el análisis de todas las obras de una fase de su vida como fijar su totalidad mediante el análisis de todas sus obras. Si todas las obras escritas entre 1770 y 1832 se nos hubieran transmitido anónimas, fracasaría todo intento de señalar entre el caos de las transmitidas las pertenecientes al individuo Goethe.»

19. Eugene A. Nida, y Charles R. Taber, La Traducción: teoría y práctica, Madrid, Ediciones Cristiandad, 1986 (1974). 
limitado nuestro análisis a un número reducido de rasgos lingüísticos para poder demostrar que se trata de fenómenos recurrentes y significativos y que, por tanto, debemos considerarlos rasgos estilísticos.

El contraste entre el texto original de Buffon y el de la traducción de Clavijo y Fajardo va a permitirnos verificar la hipótesis que hemos enunciado al principio: los principales cambios que el traductor introduce en su traducción son rasgos de estilo que elige en función de su intención comunicativa, y que, además, tienen repercusiones en la consideración estilística del género.

\section{LOS RASGOS ESTILÍSTICOS DE LA HISTOIRE NATURELLE Y LOS CORRESPONDIENTES EN LA VERSIÓN ESPAÑOLA}

En este artículo, por razones de espacio, trataremos únicamente los siguientes rasgos estilísticos, que hemos elegido por ser representativos del estilo ${ }^{20}$ en ambas obras

Histoire Naturelle de Buffon

Interrogación retórica

Anáfora

Paralelismo

Estructuras bimembres o trimembres
Traducción de Clavijo y Fajardo

1. Aseveración de la presuposición

2. --- (supresión)

3. --- (supresión)

4. ---- (supresión)

Ninguno de ellos está incluido entre los numerosos rasgos que analizan Nida y Taber $^{21}$. Sin embargo, siguiendo sus criterios de clasificación, consideramos que tanto las interrogaciones retóricas como las anáforas, los paralelismos y las estructuras bimembres y trimembres son, en el caso de una obra de contenido científico como la Histoire Naturelle, rasgos formales que procuran efectos especiales.

Sabemos del interés de Buffon por conseguir ciertos «efectos» sobre los futuros lectores de su obra. Según Condorcet (op. cit., 54-56), tras leer algunos

20. Realizamos un estudio más completo en nuestra tesis doctoral.

21. Nida y Taber (op. cit., 191-192) clasifican los rasgos estilísticos en «formales» y «léxicos» y les asignan dos funciones: bien aumentar la eficacia, es decir, "la máxima facilidad de descodificación con la mínima cantidad de energía en juego»; bien producir efectos especiales, es decir, aumentar el interés, producir mayor impacto y embellecer el mensaje. Rasgos formales que procuran eficacia (idem, 192-194): sencillez en la estructura del discurso, indicadores de tipo de discurso, indicadores de transición dentro del discurso, indicadores entre períodos, indicadores de relación entre proposiciones... Rasgos formales que procuran efectos especiales (idem, 194195): estructuras complejas en el discurso, ausencia de indicadores del tipo de discurso, ausencia de indicadores de transición, construcciones paratácticas... Rasgos léxicos que procuran eficacia (idem, 195-196): palabras conocidas, palabras muy frecuentes, combinaciones familiares de palabras, combinaciones de palabras que tienen componentes semánticos «concordantes»... Rasgos léxicos que procuran efectos especiales (idem, 197-198): palabras poco conocidas, palabras infrecuentes, términos específicos y términos genéricos, combinaciones no usuales de palabras, palabras en contraste... 
pasajes a auditores improvisados, los reescribía si no habían sido entendidos o no habían causado los efectos buscados

C'étoit par un long travail qu'il parvenoit à donner à son stile, ce degré de perfection, et il continuoit de le corriger, jusqu'à ce quil eût effacé toutes les traces de travail, et qu'à force de peine, il lui eût donné de la facilité. Car cette qualité si précieuse, n’est dans un écrivain que l'art de cacher ses efforts, de présenter ses pensées, comme sill les avoit conçues d'un seul jet, dans l'ordre le plus naturel ou le plus frappant, revêtues des expressions les plus propres ou les plus heureuses; et cet art, auquel le plus grand charme du stile est attaché, n'est cependant que le résultat d'une longue suite d'observations fugitives et d'attentions minutieuses.

M. DE BUFFON, aimoit à lire ses ouvrages, non par vanité, mais pour juger par l'expérience de leur clarté et de leur effet, les deux qualités peut-être sur lesquelles on peut le moins se juger soi-même. Avec une telle intention, il ne choisissoit pas ses auditeurs : ceux que le hazard lui offroit, sembloient devoir mieux représenter le public, dont il voulait essayer sur eux la manière de sentir ; il ne se bornoit pas à recevoir leurs avis, ou plutôt leurs éloges, souvent il leur demandoit quel sens ils attachoient à cette phrase, quel impression ils avoient éprouvée; et sills n'avoient pas saisi son idée, sil avoit manqué l'effet qu'il vouloit produire, il en concluoit que cette partie de son ouvrage manquoit de netteté, de mesure ou de force, et il l'écrivoit de nouveau. Cette méthode est excellente pour les ouvrages de philosophie qu'on destine à devenir populaires, mais peu d'auteurs auront le courage de l'employer. Il ne faut pas cependant s'attendre à trouver un égal degré de clarté dans toute l'histoire naturelle ${ }^{22}$.

Por tanto, puede decirse que en su Histoire Naturelle Buffon realizó una importante labor de reescritura con vistas a provocar en sus lectores efectos especiales, quizás más propios de textos no científicos.

Ante estos rasgos, Clavijo y Fajardo -que, como traductor literario, no podía dejar de reconocer el trabajo sobre el estilo realizado por Buffon- en su traducción optó, en primer lugar, por evitar las repeticiones de estructuras (paralelismos, anáforas, estructuras de dos o más miembros), de un modo casi sistemático (veremos que las mantuvo en algunas ocasiones), con lo que su estilo se corresponde más con lo esperable en un texto científico. En segundo lugar, pensando en el tipo de lector al que se dirigía principalmente -la juventud en proceso de formación todavía- buscó la eficacia comunicativa -en paralelo a lo que había hecho al añadir ciertos tipos de notas-, y para ello

22. En esta línea, no podemos dejar de mencionar los estudios sobre obras literarias en los que se analizan las variantes estilísticas que muchos autores introducen en sus propias obras, con las importantes repercusiones significativas que ello conlleva. Podemos citar, como ejemplo, los estudios sobre la obra de autores que no cesaron de "corregirla" con variantes estilísticas a lo largo de su vida, como Juan Ramón Jiménez: M. A. Vázquez Medel, "Claves estilísticotextuales para el estudio del proceso creativo juanramoniano", en Actas del Congreso Internacional conmemorativo del centenario de Juan Ramón Jiménez, Huelva, Excma. Diputación Provincial de Huelva, Instituto de Esudios Onubenses. Tomo II, pp. 589-617. Y «Valoración estilística de variantes: Las Baladas de Primavera de Juan Ramón Jiménez», en Cauce, Revista de Filología y su Didáctica, $n^{\circ} 12,1989$, pp. 9-38. O los análisis sobre variantes estilísticas en obras concretas, como las introducidas por Gustave Flaubert en Trois contes (Introduction, notes et relevé de variantes para Édouard Maynial), Paris, Garnier Frères, 1972). 
tradujo muchas interrogaciones retóricas por las aseveraciones que presuponían (aunque mantuvo otras).

\section{Interrogaciones retóricas}

Por el análisis de textos representativos como las obras de René-Antoine F. Réaumur Memoires pour servir à l'histoire des insectes ${ }^{23}$ o de Geoffroy-SaintHilaire Philosophie anatomique ${ }^{24}$, obra compuesta también por diferentes «mémoires» según el propio autor (Préface, vii-viij), podemos ver que el uso de la interrogación retórica es habitual en el subgénero de la memoria científica del siglo XVIII y principios del XIX en Francia. Como texto escrito para ser leído ante una Academia o "société savante», este subgénero científico se caracteriza por presentar una serie de rasgos que pueden considerarse propios de la oratoria, como las exclamaciones o las interrogaciones retóricas. Estas últimas se utilizan como un tipo de argumento que puede tener, en algunos casos, una clara intención polémica. Buffon utiliza también este tipo de argumento en sus Mémoires para l'Académie Royale des Sciences, como puede verse, por ejemplo, en Mémoire sur la conservation et le établissement des forests ${ }^{25}$.

Respecto a las interrogaciones retóricas, Monière y Labbé26 afirman

Le suremploi du point d'interrogation peut signifier [...] qu'il est plus affirmatif, quil induit la réponse ou quil aime provoquer son auditoire en employant l'interrogation rhétorique, ce qui était souvent le cas chez F. Mitterrand. [...] La phrase interrogative interpelle l'auditeur pour qu'il adhère aux idées de l'orateur. Il s'agit d'une forme affirmative déguisée [...] Ce procédé de l'interrogation rhétorique enferme l'auditeur dans une conclusion à sens unique. (p. 567)

Las oraciones interrogativas retóricas se fundan, según Escandell ${ }^{27}$, «sobre creencias que se suponen compartidas», $\mathrm{y}$ «lo interesante es que el mecanismo se utiliza en ocasiones para intentar hacer pasar como algo comúnmente aceptado lo que no es más que una opinión particular del emisor» (p. 215).

Por tanto, podemos afirmar que, como rasgo formal de estilo, las interrogaciones retóricas contribuyen a crear efectos especiales, concretamente, un mayor impacto, puesto que interpelan al receptor. Dichos efectos especiales se enmarcan, en este caso, en el ámbito de la argumentación. Como

23. René-Antoine Ferchault Réaumur, Memoires pour servir à l'histoire des insectes, Paris, Imprimerie Royale, 1734. Véanse : pp. 2, 4, 5, 6, 7, 8, 9, 10, 16, 21, 22, 23, 37, 38, 57 ...

24. Geoffroy-Saint-Hilaire, Philosophie anatomique, Paris, 1822. Véanse : pp. xiv, xv, xvi ; pp. $105,114,115,127 \ldots$

25. Georges-Louis Leclerc, Mémoire sur la conservation et le établissement des forests, Mémoires de mathématique et de physique, tirés des registres de l'Académie Royale des Sciences, Année 1739 .

26. Denis Monière y Dominique Labbé, Essai de stylistique quantitative. Duplessis, Bourassa et Lévesque. $6^{\text {es }}$ Journées internationales d'Analyse statistique des Données Textuelles, 2002, pp. 561-569.

27. M. Victoria Escandell, Introducción a la Pragmática, Antrhopos y Universidad de Educación a distancia, Barcelona y Madrid, 1993. 
argumentos, las interrogaciones retóricas tienen un carácter más polémico que la aseveración que presuponen ${ }^{28}$, ya que son enunciados que interpelan al destinatario y tratan de hacerle admitir la presuposición que contienen, de obtener de él una confirmación, mientras que la aseveración no llama a la controversia.

Un claro ejemplo de ello lo tenemos en el uso que hace Buffon de este mecanismo cuando argumenta en contra de los métodos en la Botánica (entiéndase principalmente el de Linneo), postura (la de Buffon) que fue atacada, a su vez, por los defensores de los métodos (p. e. Lamoignon de Malesherbes, op. cit. 3-6). En este caso, Clavijo, que traduce todas las interrogaciones retóricas del original por aseveraciones, encabeza su traducción de la tercera interrogación con el verbo creer, con lo que queda claro que se trata de la "opinión particular» de Buffon ${ }^{29}$.

Ejemplo 1

T. I, $15-16$

car vouloir juger de la différence des plantes uniquement par celle de leurs feuilles ou de leurs fleurs, c'est comme si on vouloit conoître la différence des animaux par la différence de leurs peaux ou par celle des parties de la génération; \& qui ne voit que cette façon de connoître n'est pas une science, \& que ce n'est tout au plus qu'une convention, une langue arbitraire, un moyen de s'entendre, mais dont il ne peut résulter aucune connoissance réelle? Me seroit-il permis de dire ce que je pense sur l'origine de ces différentes méthodes, \& sur les causes qui les ont multipliéés au point qu'actuellement la Botanique elle-même est plus aisée à aprendre que la nomenclature, qui n'en est que la langue? Me seroit-il permis de dire qu'un homme auroit plutôt fait de graver dans sa mémoire les figures de toutes les plantes, \& d'en avoir des idées nettes, ce qui est la vraie Botanique, que de retenir tous les noms que les différentes méthodes donnent à ces plantes, \& que par conséquent la langue est devenue plus difficile que la science?

\section{T. I, 13-14}

pues querer juzgar de la diferencia de las plantas únicamente por las de sus hojas ó sus flores, es lo mismo que intentar conocer la diferencia de los animales por la de sus pieles, ó por la de las partes de la generacion, no pudiéndose ocultar á nadie, que este modo de conocer, léjos de ser científico, será quando mucho un convenio, un idioma arbitrario y un modo de entenderse, pero de que no puede resultar ningun conocimiento real. Permitaseme decir lo que pienso sobre el orígen de estos diferentes métodos, y sobre las causas que los han multiplicado de tal modo que actualmente no es tan dificíl aprender la misma Botánica como la nomenclatura, que no es mas que su idioma. Yo creo que necesitaria un hombre ménos tiempo para fixar en su memoira las figuras de las plantas, y tener ideas claras de todas ellas, en lo qual consiste la verdadera Botánica, que para retener todos los nombres que en los expresados métodos se dan á dichas plantas; y que por consiguiente el lenguage se ha hecho mas difícil que la ciencia.

Por otra parte, desde el punto de vista de la eficacia comunicativa, como actos de habla indirectos que son, las interrogaciones retóricas requieren

28. Dicha presuposición, dada la inversión argumentativa que suponen las interrogativas retóricas, será afirmativa si la interrogación retórica incluye una negación externa, y negativa si no la incluye.

29. En los ejemplos, indicamos primero el número del tomo (T. I, T. II) y, a continuación, la página o páginas (5-6). Señalamos con cursiva el principio y final de las interrogaciones y de las traducciones correspondientes. 
para su interpretación un mayor esfuerzo por parte del receptor; es decir, en principio, son menos eficaces (en el sentido que dan a la eficacia Nida y Taber) que la aseveración que presuponen.

Como rasgo de estilo, además, la interrogación retórica tiene menos cabida en los géneros científicos que en otro tipo de géneros, ya que es un elemento de marcado carácter subjetivo.

Teniendo en cuenta todos estos factores, consideramos que la opción de Clavijo de traducir -aunque tampoco en todos los casos, pero sí en una mayoría- las interrogaciones retóricas del texto original por la aseveración de la presuposición que contienen puede explicarse por dos motivos: por un lado, su intención de facilitar la lectura del texto, (como es patente también en la adición de ciertos tipos de notas, o en otros de los rasgos estilísticos de su versión como son la explicitación de marcadores argumentativos o los pares cuasi-sinonímicos). Por otro, la de acercar el estilo de su traducción a la de otros textos científicos marcados por una mayor objetividad. Podríamos citar, por ejemplo, la obra de W. Bowles, cuya redacción en castellano se debió a José Nicolás de Azara. No olvidemos que Clavijo y Fajardo afirma que, antes de traducir, había leído todos los libros de Historia Natural en castellano que estuvieron a su alcance ${ }^{30}$.

En el siguiente caso, se traduce la interrogación retórica por la aseveración que contiene como presuposición (ofrecemos otros ejemplos semejantes al final del trabajo).

Ejemplo 2

T. I, 14

Cependant il semble que la recherche de cette méthode générale soit une espèce de pierre philosophale pour les Botanistes, qu'ils ont tous cherchée avec des peines \& des travaux infinis; tel a passé quarante ans, tel autre en a passé cinquante à faire son système, \& il est arrivé en Botanique ce qui est arrivé en Chymie, c'est qu'en cherchant la pierre philosophale que l'on $n$ 'a pas trouvée, on a trouvé une infinité de choses utiles; \& de même en voulant faire une méthode générale et parfaite en Botanique, on a plus étudié \& mieux connu les plantes \& leurs usages: seroit-il vrai qu'il faut un but imaginaire aux hommes pour les soutenir dans leurs travaux, \& que s'ils étoient bien persuadés qu'ils ne feront que ce qu'en effet ils peuvent faire, ils ne feroient rien du tout?

En este otro caso, en el texto original, encontramos una interrogación retórica porque no hay una respuesta explícita, aunque sí un razonamiento posterior

30. «de una aplicación continua de mas de nueve años á leer y cotejar con los Autores Latinos y Franceses quantos libros Castellanos he podido adquirir ó reconocer que traten de Historia Natural, conseguí formar un mediano Vocabulario de esta Ciencia, el qual me ha sido bastante útil.» (Prólogo del Traductor, IV) 
(car quil n’y ait...) que reafirma la presuposición implícita. En cambio, en la traducción, al explicitarse la respuesta (Parece que no, y la razon es clara,) la interrogación pierde su carácter retórico. Esta respuesta aclaratoria creemos que se debe a que Clavijo prefiere facilitar la interpretación a sus lectores.

\section{Ejemplo 3}

T.II, 28

On demande comment un être produit son semblable, on répond c'est quil étoit tout produit ; peut-on recevoir cette solution? car qu'il n'y ait qu'une génération de l'un à l'autre ou qu'ily en ait un million, la chose est égale, la même difficulté reste,
T.III, 27

¡Pregúntase cómo un ser produce su semejante, y se responde que este semejante estaba ya producido! ¿Puede admitirse esta solucion? Parece que no, y la razon es clara, porque, ya sea que no haya mas de una generacion de úno á otro, ó que haya un millon de generaciones, la cosa es igual, la dificultad subsiste,

Vamos a ver ahora cómo, en otros casos, ante una serie más o menos extensa de interrogaciones retóricas en el texto de Buffon, Clavijo opta por traducir algunas por aseveraciones y mantener otra(s).

El carácter polémico y controvertible de los fragmentos en que aparece la interrogación retórica es muy evidente en el siguiente ejemplo, en el que Buffon intenta convencer al lector de la verosimilitud de sus suposiciones. En este caso, el traductor convierte las dos primeras interrogaciones en aseveraciones, pero mantiene la última, que, además, amplía incluyendo la conclusión que en el texto original aparece como aseveración.

\section{Ejemplo 4}

\section{T. I, 142}

Je sens bien qu'on pourra me dire que si l'acceleration du mouvement se fait dans la même direction, cela ne change pas le point du périhélie qui sera toujours à la surface du Soleil; mais doit-on croire que dans un torrent dont les parties se sont succédées, il n'y a eu aucun changement de direction? Il est au contraire très-probable qu'il y a eu un assez grand changement de direction, pour donner aux planètes le mouvement qu'elles ont.

On pourra me dire aussi que si le Soleil a été déplacé par le choc de la comète, il a dîu se mouvoir uniformément, \& que dès-lors ce mouvement étant commun à tout le système, il $n^{\prime} a$ dû rien changer, mais le Soleil ne pouvoitil pas avoir avant le choc un mouvement autour $d u$ centre de gravité du système cométaire, auquel mouvement primitif le choc de la comète aura ajouté une augmentation ou une diminution? \& cela suffiroit encore pour rendre raison du mouvement actuel des planètes.
T. I, 143

Bien veo se me podrá replicar que aun supuesta la aceleracion del movimiento en la misma direccion, esto no muda el punto del perihelio que estará siempre en la superficie del Sol; pero yo entiendo que léjos de creer que en un torrente, cuyas partes se succediéron, no hubo alguna mudanza de direccion, por el contrario es muy probable que la hubo, y suficiente para dar á los Planetas el movimiento que tienen.

Tambien se me podrá objetar que, si el el Sol mudó de sitio, mediante la percusion del Cometa, debió moverse uniformemente, y que en tal caso, siendo comun este movimiento á todo el sistema, no debió haber mudanza alguna; y á esto se satisface diciendo que el Sol podia tener ántes del choque un movimiento alrededor del centro de gravedad del sistema Cometario, al qual movimiento primitivo pudo añadir el choque del Cometa alguna diminucion ó aumento, y esto bastaria tambien para dar razon del movimiento actual de los Planetas. 
Enfin si l'on ne veut admettre aucune de ces suppositions, ne peut-on pas présumer, sans choque la vraisemblance, que dans le choc de la comète contre le Soleil ily a eu une force élastique qui aura élevé le torrent au-dessus de la surface $d u$ Soleil, au lieu de le pousser directement? ce qui seul peut suffire pour écarter le point $d u$ périhélie \& donner aux planètes le mouvement qu'elles ont conservé, \& cette supposition n'est pas dénuée de vraisemblance,
Pero aun cuando no quiera admitirse ninguno de estos supuestos, ¿̨no podemos presumir, sin faltar á la verosimilitud, que en el choque del Cometa contra el Sol, hubo una fuerza elástica que elevó el torrente sobre la superficie del Sol, en vez de impelerle directamente, lo qual por sí solo era bastante para desviar el punto del perihelio, y dar á los Planetas el movimiento que han conservado? Y no es inverosimil esta suposición

En este otro, en cambio, es la primera interrogación retórica la que mantiene Clavijo y Fajardo, mientras que la segunda, más extensa y compleja, la traduce por una aseveración. Que se trata en estos casos de la opinión del autor queda claro por la interpretación del traductor, que inicia dicha aseveración por el verbo creer (creo puede decirse...)

\section{Ejemplo 5}

T. I, 166-167

$\mathrm{Ne}$ doit-on pas conjecturer aussi que si l'inclinaison de l'axe de la Terre a changé, ce ne peut être qu'en vertu des changemens arrivés à la surface, puisque tout le reste du globe est homogène, que par conséquent cette variation est trop peu sensible pour être aperçue par les Astronomes, \& qu'à moins que la Terre ne soit rencontrée par quelque comète, ou dérangée par quelquiautre cause extérieure, son axe demeurera perpétuellement incliné comme il l'est aujourd'hui, \& comme il l'a toujours été ?

Et afin de n'omettre aucune des conjectures qui me paroissent raisonnables, ne peut-on pas dire que comme les montagnes \& les inégalités qui sont à la surface de la Terre, ont été formées par l'action du flux \& reflux, les montagnes \& les inégalités que nous remarquons à la surface de la Lune, ont été produites par une cause semblable; qu'elles sont beaucoup plus élevées que celles de la Terre, parce que le flux et le reflux y est beaucoup plus fort, pusquici c'est la Lune, \& là c'est la Terre qui le cause, dont la masse étant beaucoup plus considérable que celle de la Lune, devroit produire des effets beaucoup plus grands si la Lune avoit, comme la Terre, un mouvement de rotation rapide par lequel elle nous présenteroit successivement toutes les parties de sa surface; (sic) (falta el signo de interrogación en el texto)

\section{T. I, 169-170}

¿Y no podemos tambien conjeturar que, si la inclinacion del exe de la Tierra se ha mudado, solamente puede haber sido en virtud de las alteraciones acaecidas en la superficie, puesto que todo el resto del globo es homogéneo: que por consiguiente, esta variacion es demasiadamente pequeńa para que puedan percibirla los Astrónomos; y que á ménos de encontrarse la Tierra con algun Cometa ó ser trastornada por alguna otra causa exterior, su exe permanecerá perpetuamente inclinado, como se halla ahora y lo ha estado siempre?

Para no omitir conjetura alguna de las que me parecen razonables, creo puede decirse que, así como los montes y las desigualdades que hay en la superficie de la Tierra, han sido formadas por la accion del fluxo y refluxo; así tambien los montes y desigualdades que observamos en la superficie de la Luna, han sido producidas por una causa semejante: que son mucho mas elevadas que las de la Tierra, por ser allí mucho mas fuerte el fluxo y refluxo, respecto que aquí le causa la Luna y allí la Tierra, cuya masa, siendo mucho mas considerable que la de la Luna, deberia producir efectos mucho mayores, si tuviese la Luna, como le tiene la Tierra, un movimiento rápido de rotacion en cuya virtud nos presentase sucesivamente todas las partes de su superficie;

\section{Repeticiones de estructuras}

Considerando que se trata de rasgos basados en un mismo mecanismo -la repetición- y con una misma función -crear efectos especiales-, y que, 
además, en muchos casos encontramos dos o más de estos rasgos estilísticos en un mismo fragmento, veremos conjuntamente los tres rasgos que se basan en la repetición: anáforas, paralelismos, estructuras binarias y ternarias.

Buffon, como cabía esperar, no utiliza este tipo de rasgos en sus Mémoires, pero sí en su Discours sur le style ${ }^{31}$. A partir de unos pocos ejemplos, de entre los muchos que podemos encontrar en su Discours, ilustraremos el trabajo que hay tras la expresión, la búsqueda de efectos que no son ajenos, por supuesto, a la intención de dar relevancia al contenido. Así, en el párrafo siguiente, destacan las estructuras paralelas binarias y ternarias, en algunos casos con anáforas, que presentamos a continuación en un esquema

Elle est bien différente de cette facilité naturelle de parler, qui n'est qu'un talent, une qualité accordée à tous ceux dont les passions sont fortes, les organes souples et l'imagination prompte. Ces hommes sentent vivement, s'affectent de même, le marquent fortement au dehors; et, par une impression purement mécanique, ils transmettent aux autres leur enthousiasme et leurs affections. C'est le corps qui parle au corps; tous les mouvements, tous les signes, concourent et servent également. Que faut-il pour émouvoir la multitude et l'entraîner? Que faut-il pour ébranler la plupart même des autres hommes et les persuader? Un ton véhément et pathétique, des gestes expressifs et fréquents, des paroles rapides et sonnantes. Mais pour le petit nombre de ceux dont la tête est ferme, le goût délicat et le sens exquis, et qui, comme vous, Messieurs, comptent pour peu le ton, les gestes et le vain son des mots, il faut des choses, des pensées, des raisons; il faut savoir les présenter, les nuancer, les ordonner: il ne suffit pas de frapper l'oreille et d'occuper les yeux; il faut agir sur l'âme et toucher le cour en parlant à l'esprit.

- les passions sont fortes, les organes souples et l'imagination prompte.

- $\quad$ sentent vivement, s'affectent de même, le marquent fortement

- leur enthousiasme et leurs affections

- $\quad$ tous les mouvements, tous les signes, concourent et servent

- Que faut-il pour émouvoir la multitude et l'entraîner?

Que faut-il pour ébranler la plupart même des autres hommes et les persuader?

- Un ton véhément et pathétique, des gestes expressifs et fréquents, des paroles rapides et sonnantes.

- la tête est ferme, le goût délicat et le sens exquis,

- le ton, les gestes et le vain son des mots

- il faut des choses, des pensées, des raisons

- il faut savoir les présenter, les nuancer, les ordonner

- de frapper l'oreille et d'occuper les yeux

- il faut agir sur l'âme et toucher le cour

Otro ejemplo lo encontramos en los tres párrafos que dedica a la crítica de los que, sin ideas, pretenden escribir obras «bellas» y atractivas por la expresión. La unidad temática de los tres viene marcada por la anáfora y la repetición de la estructura

31. Discours sur le style. Discours prononcé à l'Académie Francaise par M. De Buffon le jour de sa reception le 25 Aout 1753. Texte de l'édition de l'abbé J. Pierre, Librairie Ch. Poussielgue, Paris, 1896. 
- Rien ne soppose plus à la chaleur, que le désir de mettre par-tout des traits saillans [...]

- Rien n'est encore plus opposé à la véritable éloquence, que l'emploi de ces pensées fines, et la recherche de ces idées légères, déliées, sans consistance [...]

- Rien n'est plus opposé au beau naturel, que la peine qu'on se donne pour exprimer des choses ordinaires ou communes, d'une manière singulière ou pompeuse [...]

Estos ejemplos, junto a otros muchos que se podrían señalar, permiten caracterizar el tono del Discours como oratorio. La distribución de elementos en la oración es determinante: se aprecia una tendencia general al paralelismo, que se organiza en secuencias binarias y ternarias ${ }^{32}$.

En la Histoire Naturelle, la presencia de este tipo de recursos es más sorprendente por tratarse de una obra de carácter científico; y veremos cómo la versión de Clavijo y Fajardo se caracteriza, en general, por suprimir este tipo de rasgos. Ofrecemos a continuación algunos ejemplos significativos que iremos comentando. Para cada uno, presentamos el contraste entre los rasgos estilísticos del original y los de la traducción ${ }^{33}$.

En los ejemplos que vamos a ver, el traductor recurre a distintos mecanismos (alteración del orden sintáctico, uso de estructuras sintácticas diferentes, elipsis...) que iremos detallando; pero el resultado final es que anáforas, paralelismos y estructuras binarias y ternarias desaparecen en la traducción, por ello hablamos de «supresión».

En este fragmento, Clavijo y Fajardo evita las repeticiones: las anáforas (lorsqu; qu'on puisse) y los paralelismos sintácticos del texto de Buffon.

Ejemplo 6

T. I, 5

Mais lorsqu'on est parvenu à rassembler des échantillons de tout ce qui peuple l'Univers,

Lorsqu'après bien des peines on a mis dans un même lieu des modèles de tout ce qui se trouve répandu avec profusion sur la terre,

\& qu'on jette pour la première fois les yeux sur ce magasin rempli de choses diverses, nouvelles \&́étrangères,

T. I, 3

Pero supongamos que se haya conseguido juntar muestras de quanto puebla el Universo, y colocar en un Gabinete, a costa de muchos afanes, modelos de quanto hay esparcido con tanta profusion por toda la tierra

Con esa misma intención, usa estructuras sintácticas distintas, como observamos en la comparación siguiente

Ejemplo 7

T. I, 5

la première sensation qui en résulte, est un étonnement mélé d'admiration,

\& la première réflexion qui suit, _ est un retour humiliant sur nous-mêmes.

32. George Molinié, Éléments de stylistique française, Paris, PUF, 1991, p. 159.

33. Marcamos con cursiva, con subrayado o con corchetes los elementos que nos interesa destacar en cada caso. 


\section{T. I, 3}

la primera sensacion que experimentamos [la primera vez que tendemos la vista por aquel almacen, lleno de producciones diversas, nuevas y peregrinas,] es un espanto mezclado de admiracion;

y nuestra primera reflexîon, volver sobre nosotros mismos y humillarnos

\section{Y suprime las repeticiones}

\section{Ejemplo 8}

\section{T. I, 5}

On ne simagine pas qu'on puisse avec le temps parvenir au point de reconnoître tous ces différens objets, qu'on puisse parvenir non-seulement à les reconnoître par la forme, mais encore à savoir tout ce qui a rapport à la naissance, la production, l'organisation, les usages, en un mot à l'histoire de chaque chose en particulier.

T. I, 3

Parécenos imposible llegar con el tiempo á conocer toda aquella diversidad de objetos, no solo por su forma, sino tambien por lo concerniente á su origen, produccion, organización y usos, en suma, la historia particular de cada cosa;

Con estos cambios (ejemplos 6 a 8), desaparece de la traducción el ritmo creado en el texto original por las estructuras trimembres (lorsqu'on est..., lorsquiaprès... \& qu'on jette...) y bimembres, y el énfasis que implica la repetición de todos estos elementos para subrayar la dificultad que supone la creación de un gabinete de Historia Natural.

En este caso, el paralelismo del original, con ampliación en el segundo miembro, es alterado en la traducción con la elipsis verbal (que indicamos con corchetes) y un cambio de orden. Se pierde también una parte del énfasis que supone la repetición de elementos en el original.

\section{Ejemplo 9}

T. I, 11

Quelle idée de puissance ce spectacle ne nous offre-t-il pas?

quel sentiment de respect cette vue de l'Univers ne nous inspire-t-elle pas pour son Auteur!

\section{T. I, 8-9}

¡Que idea de poder no debe darnos este espectáculo!

¡Y que respeto [ ] inspirarnos hácia su Autor la vista del Universo!

En el caso siguiente, en la traducción desaparecen las anáforas (en vain, à ce) y los paralelismos (sujeto + verbo: l'éducation voudroit / les pères contraignent-ils I cette première étincelle de génie, ce germe de goût / les différentes circonstances $\&$ les différens objets), y la reiteración de estructuras binarias (en vain... en vain.... I à ce point... à ce degré... I cette première étincelle de génie, ce germe de goût / les différentes circonstances \& les différens objets), que son repeticiones que enfatizan el significado y crean, además, un ritmo más característico de los textos poéticos que de los científicos.

\section{Ejemplo 10}

T. I, 7

en vain l'éducation voudroit y suppléer,

en vain les pères contraignent-ils leurs enfans, 
il ne les amèneront jamais qu â ce point commun à tous les hommes,

à ce degré d'intelligence \& de mémoire qui suffit à la société ou aux affaires ordinaires;

T. I, 5

[y] siendo inútil pretender suplirle por medio de la educación,

sería [aun mas] infructuoso que los padres violentasen a sus hijos,

[pues] jamas conseguirian [por estos medios] que pasasen de aquel mediano grado de inteligencia y memoria, que es comun á todos los hombres, y solo suficiente para la sociedad ó para los negocios ordinarios,

T. I, 7

mais c'est à la Nature à qui on doit cette première étincelle de génie, ce germe de goût dont nous parlons,

qui se développe ensuite plus ou moins,

suivant les différentes circonstances \& les différens objets.

T. I, 5

siendo la misma Naturaleza la que da la primera centella de genio

$y$ hace brotar la aficion de que hablamos,

la qual se explaya despues mas ó ménos,

segun la diversidad de circunstancias $y$ de objetos.

En el caso siguiente, la extensa anáfora Me seroit-il permis de dire, que seńala una estructura binaria en la argumentación del autor, desaparece en la traducción. Con este recurso del énfasis, Buffon insiste en los perjuicios que, en su opinión, los distintos métodos botánicos y sus nomenclaturas causan en el aprendizaje de la Botánica. En la traducción, esta estructura binaria es mucho menos evidente por la ausencia de dicha anáfora.

\section{Ejemplo 11}

T. I, 15-16

Me seroit-il permis de dire ce que je pense sur l'origine de ces différentes méthodes, \& sur les causes qui les ont multipliéés au point qu'actuellement la Botanique elle-même est plus aisée à aprendre que la nomenclature, qui n'en est que la langue?

Me seroit-il permis de dire qu'un homme auroit plutôt fait de graver dans sa mémoire les figures de toutes les plantes, \& d'en avoir des idées nettes, ce qui est la vraie Botanique, que de retenir tous les noms que les différentes méthodes donnent à ces plantes, \& que par conséquent la langue est devenue plus difficile que la science?

\section{T. I, 13-14}

Permitaseme decir lo que pienso sobre el orígen de estos diferentes métodos, y sobre las causas que los han multiplicado de tal modo que actualmente no es tan dificíl aprender la misma Botánica como la nomenclatura, que no es mas que su idioma.

Yo creo que necesitaria un hombre ménos tiempo para fixar en su memoira las figuras de las plantas, y tener ideas claras de todas ellas, en lo qual consiste la verdadera Botánica, que para retener todos los nombres que en los expresados métodos se dan á dichas plantas; y que por consiguiente el lenguage se ha hecho mas difícil que la ciencia.

Como podemos apreciar a continuación, el paralelismo con una mínima variación (la segunda estructura paralela tiene dos elementos menos que la primera) del texto original no se reproduce en la traducción sino con muchas más variaciones, por lo que el efecto es menos evidente. 
Ejemplo 12

T. I, 29

combien de remèdes excellens la Médecine n'a-t-elle pas tiré de certaines productions de la Nature jusqu'alors inconnues!

combien de richesses

les Art n’ont-ils pas trouvé dans plusieurs matières

autrefois méprisées!

T. I, 27

Si se trata de la Medicina, son innumerables los remedios excelentes que ha sacado de las producciones de la naturaleza, desconocidas hasta que se estudió la Historia de esta;

y si de las Artes, nadie ignora las riquezas que han encontrado en materias despreciadas en otro tiempo;

Como vemos en la comparación siguiente, en el texto original existe una anáfora (où nous pouvons...) que, al mismo tiempo, forma parte de una estructura ternaria paralela. En la traducción, no se mantienen estos rasgos basados en la repetición, pues se utilizan estructuras sintácticas distintas (en este caso, con dos construcciones de gerundio -comparando, abriendo- para el segundo y tercer elemento). Desaparece así el efecto de la reiteración, tanto fonética como estructural, que crea efectos rítmicos y de insistencia.

Ejemplo 13

T. I, 50-51

arriver à ce haut degré de connoissance où nous pouvons juger que les effets particuliers dépendent d'effets généraux, où nous pouvons comparer la Nature avec elle-même dans ses grandes opérations, \& d'où nous pouvons enfin nous ouvrir des routes pour perfectionner les différentes parties de la Physique.

T. I, 48-49

á tan alto grado de conocimiento que podamos decidir que tales efectos particulares dependen de otros [mas] generales, comparando la Naturaleza con ella misma en sus grandes operaciones, y abriendo nuevos caminos para perfeccionar las diferentes partes de la Física.

También en la serie anafórica (il faut... il faut... il faut...) el traductor suprime el tercer elemento, con los mismos efectos de pérdida que ya hemos señalado en el énfasis del contenido y en el ritmo.

Ejemplo 14

T. I, 50-51

mais il faut ici quelque chose de plus, il faut des vues générales, un coup d’ail ferme \& un raisonnement formé plus encore par la réflexion que par l'étude; il faut enfin cette qualité d'esprit

T. I, 48-49

pero aun se necesita mas para lo segundo, [pues] se necesitan ideas generales, penetracion, un raciocinio formado mas bien por la reflexîon que por el estudio, y finalmente [ ] aquella comprehension

En este último fragmento, la estructura ternaria de tres infinitivos (saisir, rassembler \& former) con la misma función sintáctica, desaparece, pues el traductor utiliza dos formas personales y un gerundio (reuniéndolas). En el último paralelismo, aunque lo mantiene, elimina también la repetición de haber, con lo que se ve afectado, asimismo, el ritmo fonético. 


\section{Ejemplo 15}

\section{T. I, 50-51}

il faut enfin cette qualité d'esprit qui nous fait saisir les rapports éloignés,

les rassembler

\& en former un corps d'idées raisonnées,

après en avoir apprécié au juste les vraisemblances

$\circlearrowleft$ en avoir pesé les probabilités

T. I, 48-49

y finalmente aquella comprehension con que percibimos las analogias mas remotas,

y reuniéndolas,

formamos de ellas un cuerpo de ideas raciocinadas,

despues de haber dado el justo precio á sus verosimilitudes

y pesado sus probabilidades.

Del mismo modo, en otro caso, el traductor decide no transferir la anáfora y el paralelismo del texto original, usando en la segunda parte (con más perfección y seguridad si...) una estructura sintáctica distinta y en la que introduce un elemento de contenido que no está en el original (perfección).

\section{Ejemplo 16}

T. I, 56

nous pourrons les savoir

d'une manière plus complète à mesure que nous nous exercerons à résoudre de nouvelles questions,

$\&$ d'une manière plus sûre à mesure que nous rechercherons les causes des difficultés.

T. I, 54

[y] podrémos saberlas

mas completamente á proporcion que nos exercitemos en resolver nuevas qüestiones,

$y$ con mas perfeccion y seguridad si indagáremos y examináremos [de raiz] las causas de las dificultades.

Asimismo, la doble construcción causal iniciada por la anáfora Comme en el original es sustituida en el primer caso en la traducción por una construcción de gerundio, y sólo se mantiene en el segundo, con lo que el efecto de reiteración y énfasis de la anáfora, que marca dos estructuras relacionadas en la argumentación, desaparece.

\section{Ejemplo 17}

T. I, 56

Comme nous sommes les créateurs de cette science, \& qu'elle ne comprend absolument rien... comme les combinaisons de ces principes \& des façons de les employer sont innombrables,

\section{T. I, 54}

Siendo nosotros los criadores de esta ciencia, y no habiendo absolutamente en ella...

[y] como las combinaciones de estos principios y de los modos de emplearlos son innumerables,

En el ejemplo siguiente, Buffon se vale de la repetición sintáctica y léxica para los dos primeros miembros de la estructura ternaria, e introduce una mínima variación en el tercero. En cambio, Clavijo evita la repetición sintáctica -empleando tres estructuras completamente distintas- y léxica. 
Ejemplo 18

T. II, 262

$$
\begin{aligned}
& \text { on ne peut pas dire que ce soient des animaux, } \\
& \text { on ne peut pas dire que ce soient des végétaux, }
\end{aligned}
$$

$\&$ assurément on dira encore moins que ce sont des minéraux.

T. III, 276

los quales ni puede decirse que son animales, ni tampoco les corresponde el nombre de vegetales, y seguramente no habrá quien se atreva á darles el de minerales.

En este otro caso, mediante la pronominalización, el traductor evita el paralelismo estricto del original.

Ejemplo 19

T. II, 327

celle du mâle est un extrait de toutes les parties $d u$ corps $d u$ mâle,

celle de la femelle est un extrait de toutes les parties du corps de la femelle

T. III, 349

el del macho es un extracto de todas las partes de su cuerpo,

como el de la hembra lo es de todas las partes del cuerpo de ésta

En este último ejemplo son la elipsis y el quiasmo los mecanismos a los que recurre el traductor para evitar el paralelismo estricto del texto original.

Ejemplo 20

T. II, 339

qui seroit femelle si le premier étoit mâle,

\& qui seroit mâle si le premier étoit femelle,

T. III, 361

que seria hembra si el primero era macho,

y macho si era hembra el primero,

En los quince ejemplos que acabamos de presentar hemos visto cómo Clavijo y Fajardo evita, de modo casi sistemático, trasladar a su traducción las repeticiones características del texto de Buffon. Para ello se vale de la variación sintáctica, de la elipsis, de la pronominalización, del quiasmo o de otros tipos de alteración del orden de los elementos sintácticos. Y podemos afirmar que esta evitación es consciente porque, significativamente, en un caso que veremos a continuación Clavijo reproduce en su traducción el paralelismo y las repeticiones del original sin el menor cambio, realizando una traducción literal. Esto significa que, si ha mantenido el paralelismo y las abundantes repeticiones en este caso, podría haberlo hecho en los restantes (en la medida de lo posible, según la índole del castellano y buscando equivalencias funcionales, por supuesto).

\section{Ejemplo 21}

T. II, 342

Dans cette supposition, les molécules organiques, qui, dans le mélange des liqueurs

\section{T. III, 363-364}

En esta suposicion, las moléculas orgánicas, que en la mezcla de los licores 
séminales des deux individus, représentent les parties sexuelles du mâle, seront les seules qui pourront servir de base ou de point d'appui aux molécules organiques qui proviennent de toutes les parties du corps de la femelle, \& de même les molécules organiques qui, dans ce mélange, représentent les parties sexuelles de la femelle, seront les seules qui serviront de point d'appui aux molécules organiques qui proviennent de toutes les parties du corps du mâle, seminales de los dos individuos, representanlas partes sexûales del macho, serán las únicas que podrán servir de basa ó de punto de apoyo á las moléculas orgánicas que provienen de todas las partes del cuerpo de la hembra, del mismo modo que las moléculas orgánicas que, en la mezcla representan las partes sexûales de la hembra, serán las únicas que sirvan de apoyo á las moléculas orgánicas que provienen de todas las partes del cuerpo del macho

Con el análisis de estos ejemplos hemos querido demostrar que la Histoire Naturelle de Buffon posee una dimensión estética, extraña en una obra de Historia Natural, que fue una de las razones, y no de las menores, de su enorme éxito entre un público no especializado y heterogéneo. Las anáforas, paralelismos, estructuras binarias y ternarias son rasgos estilísticos que contribuyen a crear esos efectos buscados por el autor y que Condorcet critica en su envenenado Éloge. Como recurso de la argumentación, las interrogaciones retóricas evidencian la subjetividad del autor y destacan el carácter dialéctico y polémico de su discurso, con el que interpela directamente al lector y busca su aquiescencia ante conjeturas e hipótesis no probadas. Tratándose de una obra no destinada a ser leída ante un auditorio de savants, a diferencia de las memorias científicas, las interrogaciones retóricas alejan también la obra de la tendencia a la objetividad, característica del discurso científico frente a otro tipo de discursos.

Clavijo y Fajardo, en cambio, dirige su traducción a un público muy concreto, la juventud, con la finalidad de promover en ella el gusto por el estudio y el cultivo de la Historia Natural. Su intención comunicativa es, por tanto, facilitar la lectura de la obra, mediante una serie de mecanismos que, en ningún caso, afectan a la integridad del contenido científico. Además de las interesantes notas a pie de página -para aclarar términos especializados, y completar y actualizar la información-, realiza una serie de cambios estilísticos. Dicho cambios están destinados tanto a facilitar la comprensión -es el caso de la traducción de las interrogaciones retóricas por la aseveración de su presuposición-, como a diluir la dimensión estética de la obra original -evitando anáforas, paralelismos, estructuras binarias y ternarias mediante la elipsis, la pronominalización o los cambios de estructura sintáctica. Todos ellos contribuyen a disminuir la subjetividad y, sobre todo, los efectos especiales; $y$, por tanto, acercan el estilo de la versión española a la «langue des naturalistes».

\section{Ejemplos de interrogaciones retóricas}

En los primeros ejemplos, ofrecemos casos en que las interrogaciones retóricas son traducidas por la aseveración contenida como presuposición en aquellas. 


\section{Ejemplo 22}

T. I, 14

Cependant il semble que la recherche de cette méthode générale soit une espèce de pierre philosophale pour les Botanistes, qu ils ont tous cherchée avec des peines o des travaux infinis; tel a passé quarante ans, tel autre en a passé cinquante à faire son système, \& il est arrivé en Botanique ce qui est arrivé en Chymie, c'est qu'en cherchant la pierre philosophale que l'on n'a pas trouvée, on a trouvé une infinité de choses utiles; \& de même en voulant faire une méthode générale et parfaite en Botanique, on a plus étudié \& mieux connu les plantes \& leurs usages: seroit-il vrai qu'il faut un but imaginaire aux hommes pour les soutenir dans leurs travaux, \& que s'ils étoient bien persuadés qu 'ils ne feront que ce qu'en effet ils peuvent faire, ils ne feroient rien du tout?

\section{Ejemplo 23}

T. I, 141

D'ailleurs ne peut-on pas répondre à cette objection que le Soleil ayant été frappé par la comète, \& ayant reçu une partie de son mouvement d'impulsion, il aura lui-même éprouvé un mouvement qui l'aura déplacé, \& que quoique ce mouvement du Soleil soit maintenant trop peu sensible pour que dans de petits intervalles de temps les Astronomes aient pu l'apercevoir, il se peut cependant que ce mouvement existe encore, \& que le Soleil se meuve lentement vers différentes parties de l'Univers en décrivant une courbe autour du centre de gravité de tout le système?

\section{Ejemplo 24}

\section{T. I. 262-263}

Quion ne disepoint, avec un de nos plus célèbres Naturalistes, que ces pierres sont des cailloux imparfaits de différens âges, qui n'ont pas encore acquis leur perfection; car pourquoi seroient-ils tous imparfaits; pourquoi le seroient-ils tous $d u$ même côté, \& du côté qui est exposé à l'air?

\section{T. I, 12}

Sin embargo, parece que este método general es una especie de piedra filosofal para los Botánicos, pues todos la han buscado con increible afan y diligencia. Unos han consumido quarenta años, otros cincuenta en hacer su sistema; y ha sucedido en la Botánica lo que en la Química, que buscando la piedra filosofal, que no se ha hallado, se han encontrado infinitas cosas útiles. Del mismo modo, queriendo hacer un método general y perfecto de Botánica, se han conocido y estudiado mejor las plantas y sus usos. Tan cierto es que necesitan siempre los hombres un fin imaginario para continuar sus tareas, y que si estuviesen persuadidos de que no harian mas de lo que efectivamente pueden, nada harian.

\section{T. I, 142-143}

Tambien puede responderse á esta objecion, que habiendo sufrido el Sol la percusion del Cometa, y recibido parte de su movimiento de proyeccion, experimentaria él mismo un movimiento que le haria mudar de sitio, y que aunque este movimiento sel Sol sea actualmente casi imperceptible para que en pequeños intervalos de tiempo hayan podido los Astrónomos percibirle, puede con todo darse que este movimiento subsista todavía, y que el Sol se mueva lentamente hácia diferentes partes del Universo, describiendo una curva alrededor del centro de gravedad de todo el sistema;

\section{T. I, 283}

$\mathrm{Y}$ no se diga, como lo ha hecho uno de nuestros mas célebres Naturalistas, que estas piedras son pedernales imperfectos de diferentes edades, que no han llegado todavía á su madurez, porque ninguna razon aparece para que sean todos imperfectos, $n i$ para que lo sean por un mismo lado, esto es, por el lado expuesto al ayre. 


\section{Ejemplo 25}

T. II, 82

\& si vous me répondez quil y a apparence que les liqueurs séminales du mâle \&o de la femelle contiennent en effet chacune des embryons tout formés, que la liqueur du mâle ne contient que des mâles, que celle de la femelle ne contient que desfemelles; $[\ldots]$ n'aura-t-on pas raison de vous demander pourquoi cette voie de génération qui est la plus compliquée, la plus difficile \& la moins abondante en production, est celle que la Nature a préférée \& préfere d'une manière si marquée, que presque tous les animaux se multiplient par cette voie de communication du mâle avec la femelle?

\section{Ejemplo 26}

T.II, 24

nous voyons aussi qu'un orme n'est qu'un composé d'autres petits ormes, puisqu'en prenant un bout de branche ou un bout de racine ou un morceau de bois séparé du tronc, ou la graine, il en vient également un orme $[\ldots]$; \& puisque notre règle pour juger est la même, pourquoi jugerions-nous différemment?
T. III, 81

Y si $\mathrm{Vm}$. responde que hay apariencias de que los licores seminales del macho y de la hembra contienen efectivamente cada uno embriones enteramente formados, que el licor del macho no contiene sino machos, y hembras el de la hembra, [...] habrá sin duda justo motivo para preguntar qual es la causa de que esta via de generacion, la mas complicada, y tambien la mas difícil y esteril en producciones, sea la que que ha preferido y prefiere la Naturaleza con tanto esmero, que casi todos los animales se multiplican por esta via de la comunciacion del macho con la hembra,

\section{T.III, 23}

vemos tambien que un Olmo es un compuesto de otros Olmos pequeños, respecto que, si tomamos de él la punta de una vara, la extremidad de una raíz, un gajo de una rama separada del tronco, ó bien la semilla, sale igualmente un Olmo de qualquiera de estas cosas; [...]: de que se deduce que, siendo la regla que tenemos para juzgar una misma, no hay motivo para que juzguemos con diversidad.

\section{Ejemplo 27}

En este caso, traduce por una aseveración la primera, y conserva la serie final de siete interrogaciones retóricas más breves.

\section{T. II, 61-62}

car il est évident que ni la circulation du sang, ni le mouvement des muscles, ni les fonctions animales ne peuvent s'expliquer par limpulsion, ni par les autres loix de la mécanique ordinaire ; il est tout aussi évident que la nutrition, le développement é la reproduction se font par d'autres loix, pourquoi donc ne veut-on pas admettre des forces pénétrantes \& agissantes sur les masses des corps, puisque d'ailleurs nous enavons des exemples dans la pesanteur des corps, dans les attractions magnétiques, dans les affinités chimiques ? \& comme nous sommes arrivés par la force des faits \& par la multitude \& l'accord constant \& uniforme des observations, au point d'être assurés quill existe dans la Nature

\section{T. III, 60-61}

pues si es evidente que ni la circulacion de la sangre, ni el movimiento de los músculos, ni las funciones animales pueden explicarse por medio del impuso ni de las demas leyes de la Mecánica ordinaria, tambien lo es que la nutricion, el desarrollo y la reproduccion se hacen por otras leyes; y por consiguiente no hay razon para dexar de admitir fuerzas penetrantes y activas sobre las masas de los cuerpos, puesto que por otra parte tenemos exemplos de ellas en la gravedad de los cuerpos, en las atracciones magnéticas y en las afinidades quimicas; y si, por la fuerza de los hechos y por la multitud y conformidad constante y uniforme de las 
des forcces qui n'agissent pas par la voie d'impulsion, pourquoi n'emploierons-nous pas ces forces comme principes mécanique ? pourquoi les exclurions-nous de l'explication des phénomènes que nous savons qu'elles produisent? pourquoi veut-on se réduire à n'employer que la force d'impulsion ? n'est-ce pas vouloir juger du tableau par le toucher ? n'est-ce pas vouloir expliquer les phénomènes de la masse par ceux de la surface, la force pénétrante par l'action superficielle ? n'est-ce pas vouloir se servir d'un sens, tandis que c'est un autre qu'il faut employer ? n'est-ce pas enfin borner volontairement sa faculté de raisonner sur autre chose que sur les effets qui dépendent de ce petit nombre de principes mécaniques auxquels on s'est réduit. (sic) (falta el signo de interrogación). observaciones, hemos llegado á asegurarnos de que hay en la Naturaleza fuerzas que no obras por via de impulso, ¿por que no emplearémos estas fuerzas como principios mecánicos? ¿por que las excluirémos de la explicacion de los fenómenos que sabemos producen? ¿por que habemos de reducirnos á no emplear sino la fuerza del impulso? ¿No es esto querer juzgar de la pintura por el tacto? ¿no es querer explicar los fenómenos de la masa por los de la superficie, y la fuerza penetrante por la acción superficial? ¿no es intentar servirse de un sentido en cosas que pertenecen á otro? y finalmente ¿no es ceñir voluntariamente su entendimiento á raciocinar únicamente sobre los efectos que dependen de aquel corto número de principios mecánicos, de cuyo recinto se ha resuelto no salir? 